\title{
Papers
}

\section{Impact of erectile dysfunction and its subsequent treatment with sildenafil: qualitative study}

John M Tomlinson, David Wright

\begin{abstract}
Objectives To determine the effects of erectile dysfunction and to explore the impact of treatment with sildenafil (Viagra). Design An exploratory qualitative study with semistructured interviews.

Setting Men's health clinic in NHS hospital.

Participants 40 men who had had erectile dysfunction and had attended the clinic during the year before interview.

Main outcome measures Impact of erectile dysfunction on men, their expectations of sildenafil, and impact of treatment on men and their relationships. Issues explored with exploratory qualitative approach.

Results Erectile dysfunction caused serious distress to all those men who experienced it, with marked effects on their self esteem and their relationships. Sildenafil, when it worked, caused a great improvement in wellbeing. The expectations raised by media hyperbole with the launch of sildenafil had an adverse effect on the morale of those who found it did not work. When, according to the patient, treatment did not work, the distress was severe and for many confirmed their lack of self worth.

Conclusions Further study is needed to explore the feelings of men affected by erectile dysfunction and their perception of treatment. Health professionals should be aware of the extreme distress erectile dysfunction can cause.
\end{abstract}

\section{Introduction}

Research has identified a high prevalence of erectile dysfunction in men. ${ }^{1-3}$ Despite the awareness of the importance of psychogenic factors as a cause of erectile dysfunction, little is known about impact of erectile dysfunction and the effect of its subsequent treatment on the lives and wellbeing of patients.

Although it has now changed, ${ }^{145}$ until as late as the 1970 s a perception still existed that the causes of erectile dysfunction were primarily mental in origin. Masters and Johnson's influential study stated that only $5 \%$ of cases were of physical origin. ${ }^{6}$ Comparatively little attention has been given to the psychological impact of erectile dysfunction and its subsequent treatment, ${ }^{7-9}$ although there have been several quality of life studies. These studies used questionnaires that offered a series of statements or closed questions regarding the effects of impotence on the respondents but with a general lack of sensitivity to the men's feelings. ${ }^{9}$ The Massachusetts study of male ageing in 1987-9 mentioned the feelings of someone with erectile dysfunction only in a cursory way, stating that, "a man who has experienced a recent pattern of $\mathrm{ED}$ [erectile dysfunction] may be expected to be anxious, depressed and lacking self esteem and self confidence."1 Similarly, Melman and Gingell's survey of over 400 studies of the epidemiology of impotence and erectile dysfunction concluded that, "Erectile dysfunction is a common condition ... [and] ... has a negative impact on the quality of life," with little explanation of what the impact is. ${ }^{5}$

Nevertheless, some studies do suggest that the condition has a considerable psychological and social effect. ${ }^{9}{ }^{10}$ For example, the Impotence Association (now the Sexual Dysfunction Association) found that $62 \%$ of participants in their online survey felt that erectile dysfunction reduced their self esteem; $29 \%$ said their relationships had been affected; and 21\% reported that their relationship had ended as a direct consequence. The impact is compounded by considerable social stigma, with impotence as a source of jokes, limiting the extent to which men with erectile dysfunction can confide in others or approach health professionals for treatment.

In 1998, the first oral treatment for erectile dysfunction, a phosphodiesterase inhibitor called sildenafil (Viagra), became available. The assumption that sildenafil was a "cure" for erectile dysfunction raised high expectations for the treatment, sustained by high levels of media interest through television, mainstream press, and the internet. ${ }^{11-14}$ However, not all men find that the tablets work successfully, ${ }^{15}$ potentially generating further psychosocial concerns.

We carried out a qualitative study to determine the impact that erectile dysfunction had on participants' self esteem, relationships, and welfare, as well as exploring their expectations of sildenafil as a treatment and the impact its success or failure had on their morale. We did not include partners because our focus was specifically on the patient as an individual rather than on the relationship dynamics between the patient and his partner.

\section{Methods}

We undertook an exploratory qualitative study of the experiences of a random sample of 40 men prescribed sildenafil who had attended a men's health clinic in the 12 months before the study. The exploratory nature of the study is important given that no other studies seem to have examined the men's feelings and experiences in this area. Table 1 shows the age distribution of respondents. However, we do not know the age distribution of UK men with erectile dysfunction taking sildenafil ${ }^{16}{ }^{17}$ so we cannot say whether the sample was representative.

We divided the 302 new referrals to the clinic that year into two categories: those for whom sildenafil was successful and those for whom it was not. The definition of success was the patient's, which was always defined as achieving successful penetrative intercourse. Failure was not being able to get an 
Table 1 Age distribution of participants by success of sildenafil in treatment of erectile dysfunction

\begin{tabular}{lccc} 
Age (years) & Successful & Not successful & Total \\
\hline $18-24$ & 1 & 0 & 1 \\
\hline $25-34$ & 2 & 0 & 2 \\
\hline $35-44$ & 6 & 1 & 7 \\
\hline $45-54$ & 5 & 8 & 13 \\
\hline $55-64$ & 5 & 4 & 9 \\
\hline$\geq 65$ & 1 & 7 & 8 \\
\hline Total & 20 & 20 & 40 \\
\hline
\end{tabular}

erection firm enough to penetrate. Within each category, respondents were selected randomly and potential participants were then contacted by telephone. Those who were interested were sent an information sheet about the project and a consent form, until 20 in each group had agreed to participate. Only one man refused.

The age range of respondents was 22-72 years with a median age of 51.8 years. This compares with an age range of 16-84 years (median 59 years) for all 302 men who attended the clinic as new patients. All participants had first been prescribed sildenafil at the men's health clinic by JT, who discussed the treatment in a neutral manner, ensuring that any expectations of sildenafil were not altered as a result of the consultation.

We used semistructured interviews to identify and explore the range of issues concerning men's experience of taking sildenafil. This approach not only allowed us to follow up, clarify, and elaborate on topics raised by the participants, ${ }^{18}$ but, as it allowed issues to be raised during the course of the interview, it was particularly appropriate in research into sensitive topics. ${ }^{19}$ Given the sensitivity of erectile dysfunction, we considered that all participants should be interviewed by JT, who had seen them in the clinic, and not by an outside researcher. Although this could have caused problems in terms of informed consent and potential bias, these concerns were minimised through a careful recruitment procedure.

Potential participants were assured that agreeing or refusing to participate would not affect the quality of any further treatment and that all the information they provided would be held in the strictest confidence. ${ }^{20}$ We initially contacted participants by telephone, and those who were interested were sent an information sheet about the project and a consent form. Interviews took place at a convenient time and place for the participant, and written consent was obtained before the start of each interview. Most interviews were conducted in a private room in the hospital. They were audiotaped and lasted up to 45 minutes. In accordance with a semistructured approach, they were conducted with an interview guide constructed on the basis of issues defined in what little literature that does exist and JT's professional experience within the clinic. However, the guide was flexible to allow us to include new issues raised by the participant and was amended to reflect recurring themes. ${ }^{21}$

As we aimed to identify and explore the range of issues relating to participants' experiences, the data were subjected to a thematic analysis. ${ }^{22}$ In addition, and consistent with an exploratory approach, analysis occurred concurrently with data collection so that emerging themes could be explored more fully in subsequent interviews. We analysed the first six transcripts independently and met to agree a coding strategy. This coding was used for the remaining transcripts and amended as new themes emerged. Inter-rater reliability was undertaken on a sample of six transcripts, and, with a few exceptions, there was close agreement. Data were managed and retrieved with NUD*IST software.
Table 2 Number of participants* who raised main themes regarding sildenafil in treatment of erectile dysfunction

\begin{tabular}{lc} 
Theme & No of participants \\
\hline Impact of erectile dysfunction: & 12 \\
\hline Emasculation & 5 \\
\hline Depression & 6 \\
\hline Fall in self confidence & 3 \\
\hline Disbelief that it affects men below retirement age & 9 \\
\hline Belief they were letting down partners & 6 \\
\hline Anxiety that their partner would go elsewhere & 15 \\
\hline Inability to discuss problem with partner & 28 \\
\hline First heard about sildenafil via media & 11 \\
\hline Expectations of sildenafil: & 4 \\
\hline Very high & 15 \\
\hline Instant erection & $6 / 20$ \\
\hline Cure problem & $10 / 20$ \\
\hline Impact of sildenafil when successful: \\
\hline Return to manhood & $19 / 20$ \\
\hline Happy & 10 \\
\hline Impact of sildenafil when not successful: & \\
\hline Severe disappointment & \\
\hline Complaints of lack of spontaneity & \\
\hline *Total is 40 unless stated otherwise. & \\
\hline
\end{tabular}

${ }^{*}$ Total is 40 unless stated otherwise.

We carried out a process of progressive focusing and clustered the topics identified into a set of emerging themes after reading the interview transcripts. ${ }^{23}$ After this, we identified the range of responses relating to individual themes and then organised them into sub-themes (table 2).

\section{Results}

\section{Initial reaction to erectile dysfunction}

The most common initial reaction to erectile dysfunction was a sense of emasculation. For many men, the ability to perform sexually and to satisfy their partner was an important marker of their masculinity:

I suppose in the most simplistic terms, I associate getting an erection with being a man.

Their reaction was sometimes so severe that relationships, especially with their partners, were badly affected, often leading to depression.

Erectile dysfunction also affected the ability of participants to forge new relationships:

I've got to the point now where ... if I was to walk out of here and meet a drop dead gorgeous woman ... [I'd] think "Well, it's pointless chatting her up, because I can't do anything". .. You are not a man if you can't get an erection ... nobody's going to have any respect for you if you can't get a hard-on.

A decline in confidence did not just affect sexual relationships but also had an impact on day-to-day relationships with friends and work colleagues:

Oh it was knocking [my morale] terrible ... I work with other men and I think it [my impotence] knocked my confidence in certain ways. Not outwardly. Outwardly, it always seemed that I was one of the lads and that I was okay ... but inside ... I didn't feel that I was matching up to them ... I just felt that I wasn't as good as them basically.

Participants often felt isolated and were despondent because of their belief that erectile dysfunction affects only older men, so that they were "old before their time." This despondency was exacerbated by the feeling that the condition was irreversible and meant giving up sex for the rest of their lives.

I'd got to a point where I thought it's no good, I can't live like this. I was only $46 \ldots$.. I could see myself going for however much longer I've got, without ever making love again ... You feel as though you're the only one ... You're the only one in the world. 
Erectile dysfunction raised further concerns about the impact on the participants' relationships with their partners. Almost a quarter of them thought that they were "letting down their partners" by not being able to satisfy them sexually. Six were so concerned about the consequences of erectile dysfunction on their relationship that they were worried their partners would go elsewhere or, as one put it, "if I can't keep an erection, I'm not going to keep a woman." Fifteen were unable to discuss erectile dysfunction with their partners, principally because of a sense of avoidance or because they felt "belittled" by the condition.

\section{Expectations of sildenafil before treatment}

Most respondents $(n=28)$ first heard about sildenafil on television or in newspaper articles. These were news items on issues of health risks, sildenafil's introduction to the United Kingdom, and its availability on prescription, as well as being the subject of chat and comedy shows. In most cases, participants had high expectations of sildenafil before taking it, often resulting from the impact of media reporting. Many expected to gain an instant erection easily and immediately before sexual intercourse. Other expectations ranged from having a "full" and even "uncontrollable" erection to having a 100\% success rate with sildenafil:

I was expecting [sildenafil] to cure my problem instantly, to take this pill, to have an erection almost within five minutes of taking it, then perform wonderfully.

Respondents described the media coverage as giving the impression of creating an abnormally large erection or a very long lasting one:

All the media that surrounds it [sildenafil] gives you the impression that men are walking around with massive erections all the time.

I had very high expectations but then that, I suppose, is down to the media and the old stories about people taking one[sildenafil] and can't get rid of a hard-on for God knows how many hours.

\section{Reactions to successful treatment}

Most men for whom sildenafil had been successful felt happy and elated at being able to attain an erection: "I could have thrown open the window, shouted 'Eureka' ... and beat my chest like an apeman." The importance of "a return to manhood" can therefore not be underestimated in generating a sense of wellbeing and confidence:

[Erectile dysfunction] does get you down. It ... stunts your confidence because you just feel inadequate, and now I just feel more confident ... it just generally makes you feel more confident and believe more in yourself.

This confidence did not just centre around being able to perform but was also important in being able to satisfy the sexual needs of his partner.

\section{Reactions to unsuccessful treatment}

Patients' perception of failure was related to their high expectations. There was an assumption they had to take only one pill for all to be well. When this did not happen, hopes fell. Most tried again, but a second failure confirmed their negative feelings. "If I could tell you how empty I feel ... it's almost like a bereavement when you've lost something." Many believed they would never have sex again:

I thought, 'Well this is my last chance, and [then] they don't work .

.. they are supposed to work on 80 year olds and they're not even working on me'-and I felt my last chance had gone.

All respondents who thought that the treatment had been unsuccessful expressed a considerable degree of disappointment. Often respondents attributed this to media hyperbole:

There was a big hype in the press-"This is the be-all and end-all, the wonder drug." And I thought "Great, this is the way to go." And then when you try it and nothing happened-massive disappointment.

It was evident that respondents who felt devastated or who believed that there were no other possible treatments had usually had very high initial expectations of the drug and gave numerous reasons why they thought that sildenafil had been unsuccessful. Many thought the treatment was a failure because of a lack of spontaneity in having sex or because their sex life depended on therapeutic treatment:

It's not spontaneous, it's planned. I wish I didn't have to take it, obviously.

It's clinical now ... sex has become medical as opposed to spontaneous.

\section{Discussion}

Impotence has a considerable impact on men, with most more deeply shocked than generally realised, their masculinity and self esteem being particularly affected. Whether the cause is psychogenic, physical, or mixed, the effect is the same. Their sense of masculinity is battered, with profound effects on their feeling of worth to their partner and in the workplace. It is therefore important that, to make sure that treatment is effective in a man with erectile dysfunction, details of his sexual relationship with his partner should also be obtained.

The launch of sildenafil generated high, sometimes unrealistic, expectations. Where it was successful, a renewed self confidence occurred, particularly in existing relationships or in forging new ones. For some, sildenafil did not work the first time and the blow was severe. Although it is now known that with help and advice, the patient can often succeed eventually, a proportion were so disappointed that they did not try again. Many thought they had failed yet again in their life, adding to their already existing feeling of worthlessness.

Erectile dysfunction has a major psychosocial impact on men, and health professionals might well also anticipate an impact on personal relationships. The media have had a major effect on expectations of the effects of sildenafil, and in retrospect, less sensational reporting would have lowered those expectations to the patients' benefit.

We have shown that more sensitive and reliable measures need to be developed to detect the results of treatment, and especially the effects of failure, on the men with erectile dysfunction.

Contributors: JT and DW wrote this paper jointly. JT is guarantor. Funding: Pfizer.

Competing interests: JT has received an unrestricted grant from Pfizer, manufacturer of Viagra, to pay a part of the costs of this study and has also been paid by Bayer/GSK, Lilly Icos, and Pfizer to lecture about erectile dysfunction.

Ethical approval: North and Mid Hampshire Local Research Ethics Committee (LREC) 257/B.

1 Feldman HA, Goldstein I, Hatzichristou DG, Krane RJ, McKinlay JB. Impotence and its medical and psychosocial correlates: results of the Massachusetts Male Ageing Study.J Urol 1994;151:54.

2 Braun M, Wassmer G, Klotz T, Reofenrath B, Mathers M, Engleman U. Epidemiology of erectile dysfunction: results of the 'Cologne Male Survey'. Int J Impot Res 2000;12:30511.

3 McKinley JB. The worldwide prevalence and epidemiology of erectile dysfunction. Int J Imp Res 2000;12:S6.

4 Cooper AJ. Advances in the assessment of organic causes of impotence. $\mathrm{Br} J \mathrm{H} \mathrm{Med}$ 1986;36:186.

Melman A, Gingell JC. The epidemiology and pathophysiology of erectile dysfunction. J Urol 1999;161:5-11.

6 Masters WH, Johnson VE. Principles of the new sex therapy. Am J Psych 1976;133:5-54. 7 Riley AJ. Psychological impact of erectile disorder and its treatment by intravenous pharmacotherapy. J Sex Health 1994; Summer S3-5.

Fugl-Meyer AR, Lodnert G, Branholm IB, Fugl-Meyer KS. On life satisfaction in male erectile dysfunction. Int J Impot Res 1997;9:141-8.

9 Althof SE. Quality of life and erectile dysfunction. Urology 2002;59:803-10. 


\section{What is already known on this topic}

Impotence carries a social stigma and is a source for jokes

Sildenafil is the first oral treatment to be effective, and, as a result, there has been an enormous amount of media attention

\section{What this study adds}

Men are more shocked by impotence than has generally been realised, with their self esteem and sense of masculinity being severely traumatised

Personal relationships can be badly affected, embarrassment is acute, and misery is generally suffered alone as many feel unable to talk about it to their partners, friends, or colleagues, but worry about the consequences

Expectations of sildenafil are high, led by the media, and the higher the initial expectations of sildenafil, the more extreme the disappointment with failure

Patients define success or failure of treatment in their own way and if they feel sildenafil failed, they are even more devastated

10 Impotence Association. Survey 1997. London: Taylor Nelson AGB Healthcare, 1997.
11 Flixir of youth gets a rise out of old men. Independent on Sunday 26 April 1998.26.

12 Viagra Culture: From Hamburg to Hong Kong, everyone's buzzing about the impotence pill. Newsweek 22 June 1998

13 Love is the drug-Viagra is the sex sensation of the century. Sunday Times Magazine 6 September 1998:44-52.

14 Viagra rising. Gay Times Sep 1998:18-26.

15 Goldstein I, Lue TF, Padma-Nathan H, Rosen RC, Steers WD, Wicker PA. Oral sildenafil in the treatment of erectile dysfunction. N Engl J Med 1988;338:1397-404.

16 Kaye JA, Jick H. Incidence of erectile dysfunction and characteristics of patients before and after the introduction of sildenafil in the United Kingdom: cross sectional study with comparison patients. BMJ 2003;326:424-5.

17 Dunn KM, Jordan K, Croft PR, Assendelft WJJ. Systematic review of prevalence studies of common sexual problems. J Sex Marital Ther 2002;28:399-4.

18 Britten N. Qualitative research: qualitative interviews in medical research. BMJ 1995;311:251-4

19 Lee RM. Asking sensitive questions: interviewing. In: Doing research on sensitive topics. London: Sage, 1993:97-118.

20 Hoddinott P, Pill R. Qualitative research interviewing by doctors. A personal view of the opportunities and pitfalls. Fam Pract 1997;14:307-12.

21 Murphy E, Dingwall R, Greatbatch D, Parker S, Watson P. Qualitative research methods in health technology assessment: a review of the literature. Health Technol Assess 1998;2:112-8.

22 Strauss AL. Codes and coding. In: Qualitative analysis for social scientists. New York: Cambridge University Press, 1987:55-81.

23 Hammersley M, Atkinson P. The process of analysis. In: Ethnography: principles in practice. 2nd ed. London: Routledge, 1989:205-38.

(Accepted 20 February 2004)

doi 10.1136/bmj.38044.662176.EE

Men's Health Clinic, Royal Hampshire County Hospital, Winchester SO22 5DG John Tomlinson director

Macmillan Research Unit, University of Southampton, Highfield, Southampton SO17 1BJ

David Wright Macmillan research fellow

Correspondence to: J Tomlinson john@jptomlinson.comClays Farm, East

Worldham, Alton GU34 3AD 